\title{
Preconditioning and Cellular Engineering to Increase the Survival of Transplanted Neural Stem Cells for Motor Neuron Disease Therapy
}

\author{
Elena Abati ${ }^{1}$ \& Nereo Bresolin ${ }^{1,2}$ \& Giacomo Pietro Comi ${ }^{1,2}$ \& Stefania Corti ${ }^{1,2}$
}

Received: 13 May 2018 / Accepted: 7 August 2018

\begin{abstract}
Despite the extensive research effort that has been made in the field, motor neuron diseases, namely, amyotrophic lateral sclerosis and spinal muscular atrophies, still represent an overwhelming cause of morbidity and mortality worldwide. Exogenous neural stem cell-based transplantation approaches have been investigated as multifaceted strategies to both protect and repair upper and lower motor neurons from degeneration and inflammation. Transplanted neural stem cells (NSCs) exert their beneficial effects not only through the replacement of damaged cells but also via bystander immunomodulatory and neurotrophic actions. Notwithstanding these promising findings, the clinical translatability of suchtechniques is jeopardized bythelimited engraftment success and survival of transplanted cells within the hostile disease microenvironment. To overcome this obstacle, different methods to enhance graft survival, stability, and therapeutic potential have been developed, including environmental stress preconditioning, biopolymers scaffolds, and genetic engineering. Inthis review, we discuss current engineering techniques aimed at the exploitation of the migratory, proliferative, and secretive capacity of NSCs and their relevance for the therapeutic arsenal against motor neuron disorders and other neurological disorders.
\end{abstract}

Keywords Stem cell transplantation · Stem cells · Neural stem cells · Cellular engineering · Preconditioning · Motor neuron diseases · Amyotrophic lateral sclerosis · Spinal muscular atrophy

\section{Introduction}

Amyotrophic lateral sclerosis (ALS) and spinal muscular atrophies (SMAs) are severe diseases characterized by selective motor neuron degeneration. ALS is an incurable, progressive neurodegenerative disease characterized by loss of upper and lower motor neurons leading to irreversible muscular paralysis and eventually respiratory failure and death within 3 to 5 years after onset [1]. To date, only two approved therapies, riluzole and edaravone, with a minimal impact on survival, are available for ALS, along with supportive care (e.g., neurorehabilitation) [2, 3]. SMAs are inherited degenerative disorders affecting

* Stefania Corti

stefania.corti@unimi.it

${ }^{1}$ Dino Ferrari Centre, Department of Pathophysiology and Transplantation(DEPT), Neuroscience Section, University of Milan, Milan, Italy

${ }^{2}$ Neurology Unit, Foundation IRCCS Ca' Granda Ospedale Maggiore Policlinico, via F. Sforza 35, 20122 Milan, Italy motor neurons of the anterior horns of spinal cord gray matter. Proximal 5q SMA results from homozygous mutations in the survival motor neuron 1 (SMN1) gene. Nusinersen, an antisense oligonucleotide that modulates the expression of SMN2, was recently approved as the first therapy for SMA 5q. However, no effective treatment is available for other types of SMA [4].

Despite the variety of studies performed in this field, there are currently no valid therapeutic strategies capable of counteracting neuronal loss after its occurrence and regenerating the damaged central nervous system (CNS). Furthermore, the complex dynamics underlying the pathogenesis of motor neuron diseases (MNDs) and the relatively selective death of motor neurons remain elusive. Therefore, there exists an urgent need to cast a light over the cellular and molecular networks involved, to identify novel targets for drug development and to develop truly compelling therapeutic approaches. Clearly, to be applicable in MNDs, regenerative therapies should ultimately regulate or antagonize these complex pathways, thereby promoting the maintenance or restoration of motor neuron function [5]. 


\section{Neural Stem Cells}

Neural stem cells (NSC) are self-renewing and multipotent cells that can differentiate into the three major neuroectodermal lineages: neurons, astrocytes, and oligodendrocytes. During the embryonic period, NSCs reside in the neural tube, the precursor of the mammalian CNS [6], where they first differentiate into neuroepithelial cells and then into radial glial cells, the main NSCs during embryonic neurogenesis, located in the ventricular zone [6]. These stem cells proliferate and give rise to neuronal cells, which subsequently migrate radially from the ventricular zone to the cortical plate, where they settle to create the cerebral cortex [6].

Past research has shown that neurogenesis continues during adult life in discrete regions of the mammalian CNS, thus suggesting the possibility of neuronal repair after injury or in neurological conditions [7-10]. NSCs in the mammalian adult brain are located in the subventricular and subgranular zones of the hippocampal dentate gyrus and generate mature neuronal cells that appear to be involved in olfaction, learning, and memory processes $[11,12]$. In humans, NSCs have been found in the subgranular zone of the hippocampus [13]. These findings, however, have lately been challenged by a report showing that the number of hippocampal neural progenitors significantly decreases in human brains after childhood [14]. Nevertheless, a recent work by Boldrini and colleagues further supported the former hypothesis, showing that a comparable number of neural progenitor cells (NPCs) and immature and mature neurons were observed in the dentate gyrus region of the brain throughout aging [15]. The precise amount and role of NSC replication and differentiation in the human adult brain, in particular in response to injury such as stroke or neurological disease, remains a matter of debate. Furthermore, cells in the spinal cord, located near the central canal, have been suggested to serve as NSCs, as they have been shown to be able to differentiate into neurons and glia cells in vitro [16]. This theory, however, is even more controversial than neurogenesis in the adult brain, and further research is needed in order to better elucidate the true role of these cells in humans.

\section{Neural Stem Cells and Motor Neuron Diseases: Endogenous Neurogenesis}

Since the therapeutic activation and guidance of endogenous NSCs in the brain and spinal cord could be exploited for reparative purposes, defining their presence, quantity, and functionality in the healthy and diseased adult human CNS is of paramount importance. Therefore, we believe that further research in this field is essential, particularly in a disease context.
In this respect, adult transgenic human mutant SOD1 (mSOD1) mice, the most frequently used ALS transgenic model, have been shown to exhibit alterations in the adult forebrain NSC niche, with NSCs showing more vulnerability to disease than NPCs [17]. The response of NSCs to mitogen was found to be impaired in mSOD1 symptomatic and presymptomatic mice, while the proliferation and differentiation abilities of neuroprogenitors were preserved throughout the course of disease, thus making NSCs potential targets for recruitment with pharmacological stimulation or a cell source for transplantation [17]. Additionally, Chi and colleagues analyzed the activation of NPCs following motor neuron degeneration in ALS-like transgenic mice carrying a nestin enhancer-driven LacZ reporter and SOD1 mutation [18]. These authors reported an increased number of LacZpositive NPCs in the spinal cord posterior horn with disease onset, while NPC proliferation in the ventral horn was only observed during disease progression. Conversely, the numbers of progenitors in the precentral brain cortex were increased at disease onset but not during progression, whereas no significant differences could be detected in the number of hippocampal NPCs. Notably, the NPCs in the ALS models gave rise to a neuronal population in response to neurodegenerative stimuli [18]. While this study is very interesting, its possible limitation resides in the technology used to reveal neurogenesis, based on LacZ staining, which carries a risk of false-positive results.

Although further research is needed to clarify the role of endogenous NSCs in MNDs, these findings provide interesting evidence that regenerative treatment of these disorders could be pursued by stimulating and enhancing de novo neurogenesis.

Notwithstanding these exciting results, ALS-induced compensatory neurogenesis in the CNS is not powerful enough to halt disease progression in affected animals. Therefore, we need to find efficient supportive strategies in order to be able to exploit the degeneration-induced neurogenic response at a clinical level. Current cell approaches focus on two predominant modalities: stimulation of the endogenous NSC niche and transplantation of exogenous stem cells. The former approach aims at stimulating the proliferation, migration, and persistence of brain NSCs. Lessons on this topic can be learned from studies on the post-ischemic brain. After stroke, newborn cells from the dentate gyrus and the subventricular zone travel along blood vessel scaffolds and relocate to areas of damage in order to replace dying neurons [19]. However, only $20 \%$ of migrating newborn cells successfully complete the integration process [20]. Failed integration and progenitor death may also be linked to inefficient neurogenesis in MNDs. Several strategies to increase neurogenesis after ischemic stroke have been attempted in experimental models. Selective serotonin reuptake inhibitors, statins, and ascorbic acid have been shown to increase NSC proliferation and 
migration and to improve functional outcome after experimental ischemic stroke in animal models [21-23].

As an alternative to promoting endogenous neurogenesis, other cellular types, such as astrocytes, could be reprogrammed into NSCs in vivo by cocktail of NSCs or neuronal transcription factors [24]. However, this fascinating approach is still in its technological infancy.

\section{Neural Stem Cells and Motor Neuron Diseases: Cell Transplantation}

The exogenous approach is based on the transplantation of NSCs obtained from different external sources to the CNS. This strategy has already been applied in murine models of different MNDs, namely, ALS [25-27], SMA [28, 29], and SMAwith respiratory distress (SMARD1) [28,30]. Advances in stem cell biology and the use of adult somatic cells reprogrammed into induced pluripotent stem cells (iPSCs) as a possible source of NSCs have fostered basic and preclinical research in stem cell transplantation therapy [25].

Exogenous NSCs may act through a process of cellular replacement, migrating and engrafting into damaged tissues [31, 32]. However, the therapeutic effect elicited by NSCs extends beyond the replacement of injured cells. Transplanted NSCs in experimental MNDs exert trophic and immunomodulatory actions and increase host brain neural plasticity [25, 31, 32]. NSCs may lead to environmental enrichment by releasing trophic factors, scavenging toxic ones, promoting neoangiogenesis, or forming novel neural circuitries around diseased areas, eventually favoring the recovery of the injured CNS [25, 31, 32]. NSCs can also differentiate into non-neuronal progeny (oligodendrocytes, astrocytes) known to promote homeostasis and support regenerating host axons [31]. Indeed, NSCs can also elicit protection or regeneration of perilesional tissues and circuitries [31, 33]. In the past ten years, several preclinical studies focusing on the use of stem cells in ALS transgenic animal models have shown promising results [26, 27, 31, 34-37]. Furthermore, Teng and colleagues demonstrated anincreased therapeutic effect whenperforming multiple dose-escalating injections in different CNS sites, indicating the importance of administering enough cells into critically functional areas to hinder ALS-induced damage [31].

Our group recently demonstrated that isolating a specific NSC subpopulation that expresses certain surface antigens allows the employment of a discrete cellular population with stronger therapeutic effects on ALS diseasemodels.

Indeed, we described that transplantation of iPSC-derived LewisX + CXCR4 + $\beta 1$-integrin + NSCs slows motor neuronal degeneration and preserves muscle innervation in ALS human and rodent models [27]. The subpopulation positive for LewisX-CXCR4- $\beta 1$-integrin protects neurons from early degeneration and enhances axonal elongation of human ALSderived motor neurons cocultured with toxic ALS astrocytes, through inhibiting neuronal disease mechanisms (GSK3-b pathway) and blocking astrocyte activation. In vivo, this NSC subpopulation promotes neuromuscular junction integrity, induces novel axonal sprouting, and diminishes macroand microgliosis, with an overall improvement in survival and neuromuscular function in transplanted SOD1G93A mice. These results suggest that modulating multiple diseased pathways in both neuronal and glial cells could effectivelyincrease the preservation of muscular functional innervation [27].

The first safety clinical trial of direct intraspinal delivery of fetal-derived NSCs into ALS patients was approved in 2009 and has now undergone phase 2 [38-41]. The results showed that intraspinal stem cell transplantation can be safely performed at high doses and does not accelerate disease progression. Outcome analysis of the phase $1 / 2$ studies demonstrated significantly improved survival and function in comparison to that in historical datasets [42]. However, despite the encouraging results, the potential biases connected with historical controls underline the limitations of non-controlled studies and post hoc analyses, thereby stating the need for efficacy studies and sufficiently powered and randomized clinical trials.

Unfortunately, a major hurdle to successful regenerative therapy is the limited survival of transplanted cells, partly because of immunological graft rejection [43]. A postmortem study of graft survival conducted on six trial patients revealed that transplanted NSCs survived up to 2.5 years, some differentiating into neurons, while others maintained their stemness [44]. Notwithstanding these findings, several elements contribute to the rejection of transplanted stem cells in ALS. For instance, ALS progression is characterized by a concomitant multiphase immune activation, which actively shapes disease pathology and pathogenesis $[45,46]$. Likewise, the inevitable inflammation and local trauma resulting from invasive cell transplantation surgery could compromise the survival of injected cells [25]. Furthermore, the neurodegenerating environment can influence stem cell endurance. In a recent experiment, murine NSCs genetically modified to express firefly luciferase were transplanted into the cervical spinal cord of presymptomatic mutant SOD1 mice [47]. A transient improvement in locomotor function was witnessed only at early disease stages, whereas in the subsequent weeks, a sharp decline in bioluminescent imaging was found, with a complete signal loss at the endpoint. Macrophage activation, astrogliosis, and microgliosis were also noted in proximity to the transplantation site. Conversely, the bioluminescent signal intensity persisted in injected healthy controls throughout the entire study period. Thus, disease progression seems to jeopardize the survival of transplanted NSCs because of the progressive formation of a toxic spinal cord microenvironment [47]. Exposure to a hostile environment might hinder 
grafted NSC survival and therapeutic effects not only through the generation of toxic by-products but also by increasing their susceptibility to immune targeting. Indeed, although grafted NSCs elude immune targeting by expressing low levels of major histocompatibility complex (MHC) antigens, proinflammatory cytokines such as interferon $\mathrm{Y}$ may result in the upregulation of MHC expression [48].

These findings further highlight the challenges that researchers need to overcome in order to develop a successful stem cell engraftment strategy.

\section{Engineering Strategies to Enhance NSC Survival and Therapeutic Effects}

Survival of NSCs after transplantation is the prerequisite for their therapeutic effect in host tissues. However, because of the aforementioned pathological microenvironment present in MNDs and other neurodegenerative diseases, the majority of grafted NSCs undergo cell death upon transplantation [49], thus making targeted stem cell manipulation to foster survival an essential target for intervention. To this aim, different techniques have been developed, such as hypoxic or pharmacological preconditioning [50], seeding of NSCs within biomaterial scaffolds, and genetic manipulation of cells prior to transplantation [51] (Fig. 1).

\section{Hypoxic Preconditioning}

Ischemic or hypoxic preconditioning treatments have been shown to promote tolerance and regenerative properties of transplanted stem cells, increasing their resistance to low substrates and oxygen availability in degenerating tissue via adaptive responses such as the upregulation of anti-apoptotic genes (Bcl-2, HIF-1) and reduction in caspase-3 activity (Table 1) [50]. Additionally, NSCs have been hypothesized to be physiologically predisposed to anaerobic/microaerophilic metabolic patterns, which enhance self-renewal and inhibit differentiation [52]. Therefore, exposure of the cells to highly aerobic conditions, such as atmospheric oxygen, before transplantation might unwillingly compromise their survival once injected into neural tissues, especially the hypoxic/anoxic environment typical of neurodegenerative diseases [52]. Moreover, hypoxic preconditioning of transplanted NSCs has been shown to enhance the therapeutic properties of NSCs via neurotrophic secretion. Indeed, controlled hypoxia $\left(1 \% \mathrm{O}_{2}\right.$ for $4 \mathrm{~h}$ ) upregulates HIF-1 $\alpha$, neurotrophic, and growth factors including neurotrophin-3 (NT-3), glial cellderived neurotrophic factor (GDNF), and brain-derived neurotrophic factor (BDNF) [53]. Hypoxic preconditioning promotes increased expression of HIF1- $\alpha$ and HIF target genes such as erythropoietin (EPO) and vascular endothelial growth factor (VEGF), but the direct molecular mechanisms of induction of other neurotrophic factors are unknown.

In another study, Wakai and colleagues further demonstrated that mild hypoxia ( $5 \% \mathrm{O}_{2}$ for $24 \mathrm{~h}$ ) also promotes NSC proliferation and resilience to transplantation by upregulating phospho-Akt (pAkt) expression via HIF-1 $\alpha$ and subsequent expression of VEGF [33]. Akt is well known to contribute to self-renewal and differentiation in NSCs. Thus, modulating pAkt levels may directly contribute to the increase in survival of transplanted cells.

Overall, these findings suggest that hypoxic preconditioning strategies promote survival of transplanted cells, increase their neuroprotective properties, and facilitate functionalrecovery in in vivo models of neurological diseases (Table 1 ). Notably, although HIF-1 $\alpha$ and their downstream pathways appear crucial, the precise cellular mechanisms activated by hypoxic preconditioning have not been clarified yet. Direct pharmacological modulation of HIF-1 $\alpha$ could be a potential target to directly obtain the beneficial effects of hypoxic preconditioning.

To further elucidate the molecular mechanisms underlying hypoxic preconditioning, a recent study analyzed the microRNA expression profiles of exosomes derived from normal vs hypoxic preconditioned NSCs by next-generation sequencing [54]. After hypoxic preconditioning, the exosomal miRNA expression profile was modified, and some miRNAs were differentially expressed in the two populations, such as miR-98-3p. Exosomal functions changed as well, and exosomes from preconditioned cells appeared capable of modulating gene expression and promoting stroke recovery [54]. Notably, this work reveals how the administration of exosomes derived from preconditioned cells could represent an alternative approach to direct NSC transplantation, thus avoiding the risks related to the use of a cellular product.

\section{Pharmacological and Small-Molecule Preconditioning}

Furthermore, pharmacological preconditioning strategies have also been studied (Table 2). NSCs exposed to minocycline have been observed to display upregulation of Nrf2, a transcription factor that regulates the basal and inducible expression of a spectrum of antioxidant genes and the secretion of neurotrophic factors, including BDNF, nerve growth factor (NGF), GDNF, and VEGF, thereby enhancing functional recovery in vivo [55]. The positive effects of minocycline preconditioning, as well as the simplicity and lack of safety concerns, make this strategy highly suitable for future clinical applications.

Similarly, exposure to interleukin-6(IL-6) has been demonstrated to increase expression of manganese superoxide dismutase(SOD2), a primary mitochondrial antioxidantenzyme, 


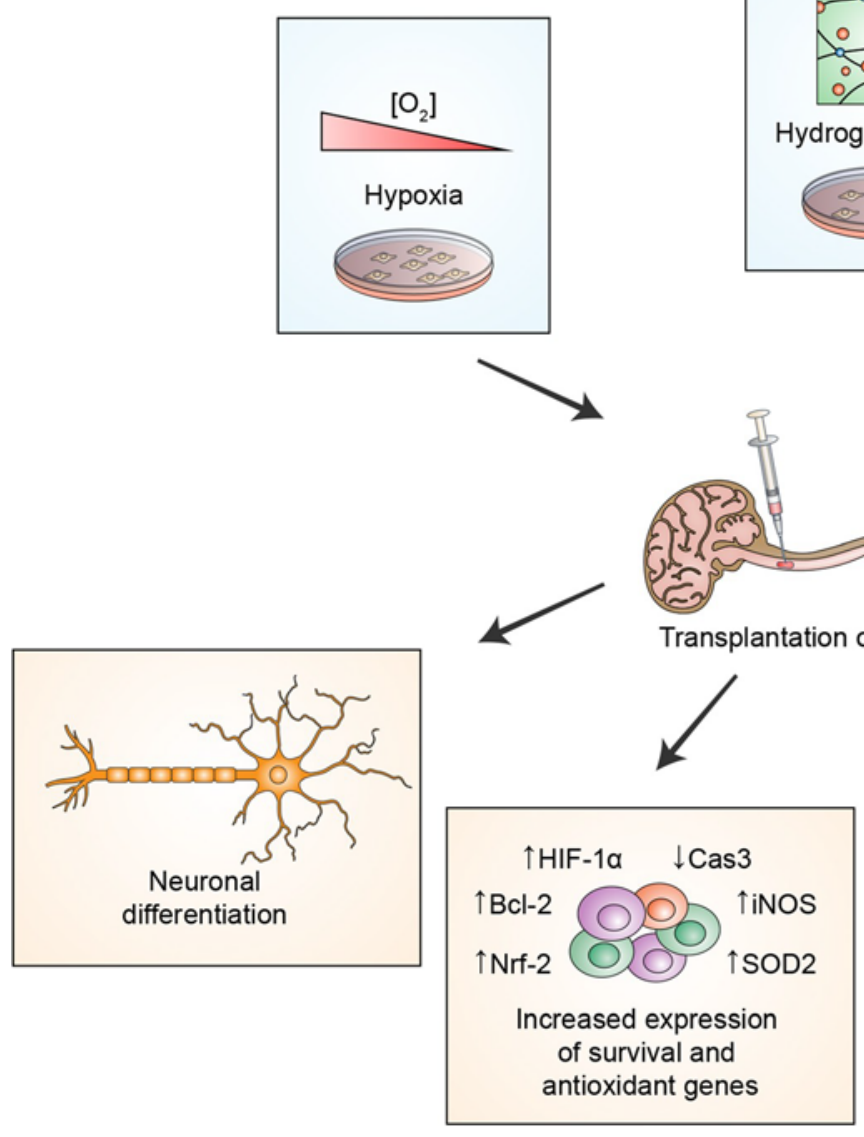

Fig. 1 Engineering strategies to increase stem cell engraftment and survival within the host tissue include hypoxic and pharmacological (minocycline, adjudin, interleukin-6, BDNF) preconditioning, seeding of cells into biomaterial scaffolds, and genetic manipulation to overexpress neurotrophic or survival genes. When transplanted into the CNS, treated cells show reduced death rates and increased proliferative abilities. Furthermore, they display enhanced neuroprotective properties,

through signal transducer and activator of transcription 3 (STAT3), thus making transplanted NSCs more resistant to oxidative stress in both in vitro and in vivo settings [56]. Indeed, IL-6 stimulation promoted secretion of VEGF from NSCs [56]. The simplicity of the use of minocycline makes it interesting for clinical translation.

Among pretreatments with neurotrophins, BDNF-treated NSCs were shown to result in higher NSC engraftment and survival, increased neuroprotection, and greater functional out-

comes in a stroke model when compared to untreated NSCs [57]. Remarkably, BDNF pretreatment promoted expression of chemokine receptors and adhesion molecules, thereby favoring not only cerebral engraftment but also migration. In addition, BDNF pretreatment of NSCs stimulated the secretion of neuroprotective peptides. Therefore, BDNF treatment of NSCs is a simple strategy that can be used to increase engraftment success.

Another small molecule tested for preconditioning is adjudin, which is currently under study as a potential non-
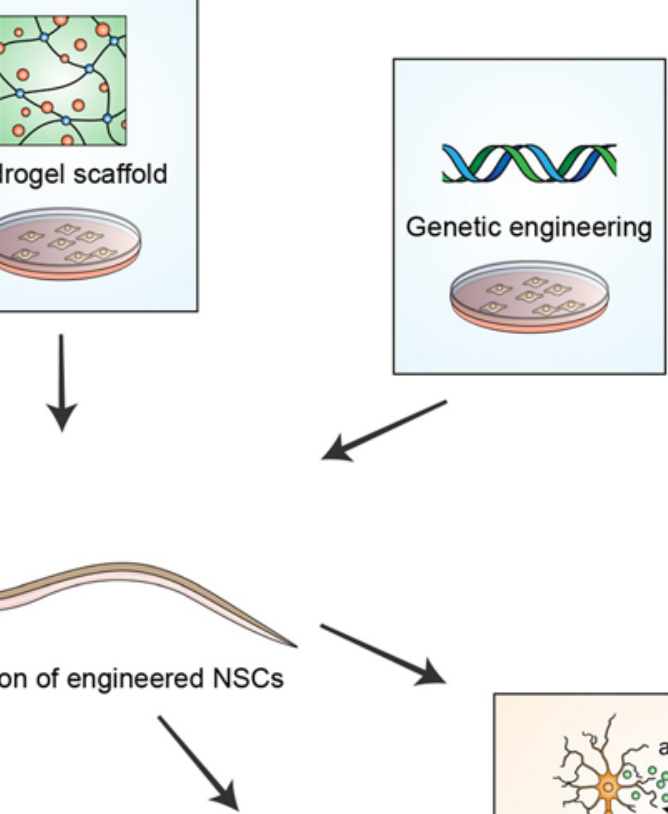

BDNF, GDNF, NGF, $\because$ VEGF, EPO

$\therefore .00$

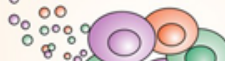

Increased neurotrophic support

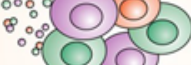

increasing endogenous neuroblasts proliferation and migration and reducing infarct size and reperfusion-induced injury in experimental models. In addition to that, engineered cells appear able to increase expression of anti-apoptotic (HIF1a, Bcl-2), antioxidant (iNOS, SOD2, catalase, Nrf2), and trophic (VEGF, EPOR) genes. Remarkably, they can also promote the secretion of neurotrophic factors (GDNF, BDNF, VEGF, NGF, NT-3) and reduce cytokine production and microglial activation

hormonal male contraceptive, given its ability to disrupt the adherens junction between germ cells and Sertoli cells without affecting testosterone production [58]. This molecule has been suggested to be neuroprotective in stroke models [59]. For this reason, pretreatment of NSCs with adjudin was attempted, resulting in intracellular inhibition of oxidative damage, activation of the NSC pro-survival Akt signaling pathway, and increased expression of BDNF, NGF, and GDNF after treatment, thereby promoting NSC survival after transplantation into an ischemic area [60].

Preconditioning can increase not only survival but also other proliferation and migration properties of NSCs. High-mobility group box 1 (HMGB1) is an inflammatory protein that exerts beneficial effects in the chronic phase following CNS injury [61]. Furthermore, HMGB1 was shown to promote NSC proliferation in vitro; thus, HMGB1 may be exploited as a preconditioning molecule. Exposure of NSCs to HMGB1 before transplantation was found to stimulate not only NSC proliferation but 
Table 1 Hypoxic preconditioning of NSCs prior to transplantation in the CNS

\begin{tabular}{|c|c|c|c|}
\hline Cell source and treatment & Experimental model & Transplantation & Outcomes \\
\hline $\begin{array}{l}\text { Mouse ESC-derived NPCs } \\
\text { exposed to } 1 \% \mathrm{O}_{2} \text { for } 8 \mathrm{~h}\end{array}$ & Rat tMCAO (120 min) & $\begin{array}{l}48 \text { h after MCAO; } \\
\text { intracerebral }\end{array}$ & $\begin{array}{l}\text { 30-40\% reduced cell death after transplantation. } \\
\text { Greaterimprovementinsensorimotorfunctionscompared } \\
\text { to the non-preconditioned group. } \\
\uparrow \text { expression of Bcl-2, NF, synaptophysin, HIF1alpha. } \\
\uparrow \text { EPO secretion. }\end{array}$ \\
\hline $\begin{array}{l}\text { Primary rat BMSCs exposed } \\
\quad \text { to } 0.5 \% \mathrm{O}_{2} \text { for } 24 \mathrm{~h}\end{array}$ & Rat tMCAO (90 min) & $\begin{array}{l}24 \mathrm{~h} \text { afterMCAO; } \\
\text { intravenous }\end{array}$ & $\begin{array}{l}\uparrow \text { survival of NSCs. } \\
\text { Greater improvement in brain functional recovery and } \\
\text { motor functions compared to thenon-preconditioned } \\
\text { group. } \\
\uparrow \text { expression of GDNF, BDNF, VEGF, VEGF receptor } \\
\text { Flk- } 1 \text { and angiotensin- } 1 \text {. } \\
\uparrow \text { expression of chemokine SDF-1 and CXCR4. } \\
\uparrow \text { EPO secretion and EPOR expression. }\end{array}$ \\
\hline $\begin{array}{l}\text { Primary rat BMSCs exposed } \\
\text { to } 0.1-0.3 \% \mathrm{O}_{2} \text { for } 24 \mathrm{~h}\end{array}$ & $\begin{array}{l}\text { Mouse, experimental ICH } \\
\text { induced with collagenase IV }\end{array}$ & $\begin{array}{l}72 \text { h or } 7 \text { days } \\
\text { after ICH; } \\
\text { intranasal }\end{array}$ & $\begin{array}{l}\uparrow \text { perilesional levels of BDNF, GDNF, and VEGF. } \\
\uparrow \text { neuroblast proliferation and migration. } \\
\text { Improved functional recovery. } \\
\downarrow \text { brain atrophy changes. }\end{array}$ \\
\hline $\begin{array}{l}\text { Mouse iPSC-derived NPCs } \\
\text { exposed to } 0.1-0.3 \% \mathrm{O}_{2} \text { for } \\
8 \mathrm{~h}\end{array}$ & Rat, stereotaxic TBI & $\begin{array}{l}72 \text { h after TBI; } \\
\text { intracerebral }\end{array}$ & $\begin{array}{l}\text { Improved sensorimotor outcome and social behaviors. } \\
\uparrow \text { expression of oxytocin and oxytocin receptor. }\end{array}$ \\
\hline $\begin{array}{l}\text { Primarymouse NSCs exposed } \\
\text { to } 5 \% \mathrm{O}_{2} \text { for } 24 \mathrm{~h}\end{array}$ & $\begin{array}{l}\text { Mouse, experimental ICH } \\
\text { induced with autologous } \\
\text { whole blood }\end{array}$ & $\begin{array}{l}72 \mathrm{~h} \text { after ICH; } \\
\text { intracerebral }\end{array}$ & $\begin{array}{l}\uparrow \text { survival of grafted NSCs. } \\
\text { Improved functional recovery. } \\
\uparrow \text { expression of HIF1alpha, phosphor-Akt, and VEGF. }\end{array}$ \\
\hline $\begin{array}{l}\text { Primary rat NSCs exposed to } \\
1 \% \mathrm{O}_{2} \text { for } 2,4 \text { or } 6 \mathrm{~h}\end{array}$ & Rat, stereotaxic SCI & $\begin{array}{l}\text { During procedure; } \\
\text { intraspinal, in } \\
\text { situ }\end{array}$ & $\begin{array}{l}\uparrow \text { locomotor recovery. } \\
\uparrow \text { neuronal survival and reduced glial scar formation. } \\
\uparrow \text { expression of GDNF, BDNF, NT-3, and HIF1alpha. }\end{array}$ \\
\hline
\end{tabular}

Abbreviations: BDNF, brain-derived neurotrophic factor; BMSCs, bone marrow mesenchymal stem cells; $E P O$, erythropoietin; EPOR, erythropoietin receptor; ESCs, embryonic stem cells; GDNF, glial-derived neurotrophic factor; $I C H$, intracerebral hemorrhage; iPSCs, induced pluripotent stem cells; $N F$, neurofilament; NPCs, neural progenitor cells; NSCs, neural stem cells; NT-3, neurotrophin-3; SCI, spinal cord injury; TBI, traumatic brain injury; $t M C A O$, transient middle cerebral artery occlusion; VEGF, vascular endothelial growth factor

also migration [61]. Therefore, targeted HMGB1 preconditioning before transplantation could enhance NSC relocalization within diseased areas of the CNS [61].

Recently, NSC pretreatment with metformin, an approved antidiabetic compound, was investigated, following the observation of a potential pro-neurogenic effect of this substance [62]. Pretreatment of human iPSC-derived NSCs with metformin enhanced both their proliferation and their differentiation in culture. Moreover, metformin-preconditioned NSCs displayed an increased engraftment with better functional outcomes in rodent stroke models. Interestingly, this strategy promoted not only cell survival but also differentiation, a useful property for clinical application.

A possible preconditioning approach that has not been investigated yet involves the use of small molecules that interfere with regulated necrosis, through substances able to modulate key enzymes of these pathways [63]. These compounds include necroptosis inhibitors such as necrostatin-1 (Nec-1) and newer molecule such as ferrostatins. This approach warrants investigation in the context of NSC transplantation.

Although whether such artificial approaches could ultimately prove relevant at a clinical level remains unclear, translational research may be advantageous due to the simple, transient, and non-integrative nature of these techniques. Additionally, the simultaneous use of several combined small molecules acting on different pathways could be explored. On the other hand, the limitations of these approaches reside on their short and temporary effect.

\section{Use of Scaffolds in NSC Transplantation}

A further innovative technique to support NSC survival and engraftment is represented by the transplantation of cells included in natural or synthetic bioengineered scaffolds. These scaffolds aim to create a more favorable environment for transplanted cells with respect to the native host tissue, thereby facilitating manipulation and transplantation phases and reducing mechanical stress.

For instance, transplanting NSCs seeded within a biopolymer hydrogel matrix was recently shown to improve the durability and performance of the graft in the host tissue [64]. The hydrogel was composed of cross-linked hyaluronan and heparin sulfate, mimicking the CNS extracellular matrix, and significantly promoted NSC engraftment after transplantation. 
Table 2 Pharmacological and small molecule-based preconditioning of NSCs prior to transplantation in the CNS

\begin{tabular}{|c|c|c|c|c|}
\hline Cell source and treatment & $\begin{array}{l}\text { Experimental } \\
\text { model }\end{array}$ & Transplantation & Outcomes & Ref. \\
\hline $\begin{array}{l}\text { Primary rat NSCs cultured with minocycline } \\
\text { hydrochloride }(10 \mu \mathrm{M}) \text { for } 24 \mathrm{~h}\end{array}$ & $\begin{array}{l}\text { Rat tMCAO } \\
\qquad(90 \mathrm{~min})\end{array}$ & $\begin{array}{l}6 \mathrm{~h} \text { after MCAO; } \\
\text { intracerebral }\end{array}$ & $\begin{array}{l}\uparrow \text { survival and proliferative capacity of } \\
\text { preconditioned grafted NSCs. } \\
\uparrow \text { expression of Nrf2 and Nrf2-regulated } \\
\text { antioxidant genes. } \\
\uparrow \text { secretion of BDNF, NGF, GDNF, and } \\
\text { VEGF. } \\
\text { Enhanced neuroprotection in ischemic area. }\end{array}$ & [55] \\
\hline $\begin{array}{l}\text { Primary mouse NSCs cultured with IL-6 } \\
\text { (20 ng/ml) for } 24 \mathrm{~h}\end{array}$ & $\begin{array}{l}\text { Mouse tMCAO } \\
\quad(45 \mathrm{~min})\end{array}$ & $\begin{array}{l}6 \text { h or } 7 \text { days after } \\
\text { MCAO; intracerebral }\end{array}$ & $\begin{array}{l}\uparrow \text { survival and } \downarrow \text { death of grafted cells. } \\
\uparrow \text { expression of SOD2. } \\
\uparrow \text { in vitro and in vivo angiogenesis. } \\
\downarrow \text { infarct size. } \\
\text { Improved functional recovery (rotarod test). }\end{array}$ & {$[56]$} \\
\hline $\begin{array}{l}\text { Human ESC-derived NSCs cultured with BDNF } \\
\text { (100 ng/ml) for } 1 \mathrm{~h}\end{array}$ & $\begin{array}{l}\text { Mouse tMCAO } \\
\quad(15 \mathrm{~min})\end{array}$ & $\begin{array}{l}72 \text { h after MCAO; } \\
\text { intra-arterial (carotid) }\end{array}$ & $\begin{array}{l}\uparrow \text { NSC engraftment and survival in host } \\
\text { brain. } \\
\text { Improved functional recovery (horizontal } \\
\text { ladder test). } \\
\text { Enhanced neuroprotection in ischemic area. } \\
\uparrow \text { secretion of ICAM-1, VCAM-1, and } \\
\text { VEGF. }\end{array}$ & {$[57]$} \\
\hline $\begin{array}{l}\text { Primary mouse NSCs cultured with adjudin }(5,10 \text {, } \\
30 \text {, or } 60 \mu \mathrm{M}) \text { for } 24 \mathrm{~h}\end{array}$ & $\begin{array}{l}\text { Mouse tMCAO } \\
\quad(120 \mathrm{~min})\end{array}$ & $\begin{array}{l}24 \mathrm{~h} \text { after MCAO; } \\
\text { intracerebral }\end{array}$ & $\begin{array}{l}\uparrow \text { expression of antioxidant genes (iNOS, } \\
\text { SOD2, catalase). } \\
\uparrow \text { secretion of neurotrophic factors (BDNF, } \\
\text { GDNF, NGF). } \\
\downarrow \text { cytokine production and microglial } \\
\text { activation. } \\
\downarrow \text { infarct size. } \\
\text { Enhanced neuroprotection and angiogenesis } \\
\text { in ischemic area. } \\
\text { Improved functional recovery (rotarod test). } \\
\text { Reduced ischemia/reperfusion-induced } \\
\text { blood-brain barrier leakage. }\end{array}$ & {$[60]$} \\
\hline
\end{tabular}

Abbreviations: BDNF, brain-derived neurotrophic factor; ESCs, embryonic stem cells; GDNF, glial-derived neurotrophic factor; iNOS, inducible nitric oxide synthase; $I L-6$, interleukin-6; NGF, nerve growth factor; NSCs, neural stem cells; tMCAO, transient middle cerebral artery occlusion; VEGF, vascular endothelial growth factor

Such hydrogel matrices could also be Bfunctionalized.^ For instance, Adil and colleagues supplemented a hyaluronic acid hydrogel with arginylglycylaspartic acid and heparin via click chemistry and tailored its stiffness to improve neuronal cell graft survival [65]. Cells were cultured and harvested within the scaffold to reduce mechanical and enzymatic stress. Remarkably, after transplantation, hydrogel-encapsulated cells had a fivefold higher survival rate than unencapsulated donor cells, suggesting that the bioscaffold approach can greatly improve transplantation efficacy.

Furthermore, scaffolds can be used as a depot release for growth factors to promote transplant stem cell survival and differentiation. Moshayedi and colleagues engineered a hyaluronic acid-based self-polymerizing hydrogel by inserting growth factors, BNDF or BMP-4, and heparin into the hyaluronic acid backbone in order to promote their retention [66].

Recently, Soma and his team developed an injectable biological substrate that self-assembles within the host tissues froma laminin-derived epitope, thereby mimicking the brain's major extracellularprotein, supportinglong-term survival and functional maturation of NSCs [67]. Remarkably, scaffolds assembled with conductive polymers were shown to allow electrical stimulation of NSCs before transplantation, with enhanced functional recovery [68]. This strategy is based on a combination of the scaffolding technology with preconditioning treatment. Electrical stimulation of human NSCs changes the expression pattern of genes, in particular VEGF-A pathway genes and genes involved in cell survival. Upon transplantation, electrically preconditioned NSCs more effectively improved functional outcomes in animal models than did unstimulated NSCs. The use of scaffolds to influence the NSC transcriptome provides an additional opportunity to optimize NSC-based approaches.

Overall, these findings suggest that acting on the local environment promotes the success and efficacy of NSC transplantation. This evidence advocates for the refinement of scaffolding technology in order to boost the therapeutic arsenal of stem cell-based regenerative medicine. 


\section{Ex Vivo Genetic Modification to Increase NSC Engraftment}

Ex vivo genetic engineering could also be exploited to tune the expression of genes involved in NSC function in order to tailor the NSC proteome and secretome to the therapeutic needs of MNDs [69]. Indeed, in addition to graft survival, gene therapy could also be used to maximize the therapeutic potential of NSCs by selectively altering their secreted products [69]. NSCs genetically modified to overexpress different neurotrophic genes (GDNF, BDNF, neurotrophin-3, NGF) have shown improved survival rates and enhanced proliferative and neuroprotective properties in the context of neurological diseases and MNDs [70-76]. In a recent study, human cortical-derived NSCs were engineered to secrete GDNF and transplanted into the SOD1G93A ALS rat cortex [76]. The cells were able to migrate and differentiate mainly into GDNF-producing astrocytes. This treatment resulted in the preservation of motor neurons and amelioration of disease pathology. These NSCs administered into the cortex of nonhuman primates survived and presented robust GDNF expression without adverse effects. This study suggests a synergic effect of GDNF and NSC transplantation and the superiority of this combined approach compared to the effects of GDNF or NSC treatment alone shown in previous studies. Thus, the transplantation of genetically modified stem cells represents a possible therapeutic strategy for MNDs to be further explored.

In addition to genetic modification of growth factors, overexpression of SOD2 to lower free radicals reduces NSC death rates after transplantation in a stroke model and suppresses the generation of reactive oxygen species after reperfusion injury [77]. Thus, other candidate genes could be explored for ex vivo genetic modifications of NSCs prior to transplantation.

Strikingly, while previous studies focused on the selective manipulation of distinct genes or proteins in NSCs, recent discoveries have highlighted manifold processes, such as global SUMOylation, which appear to protect cell homeostasis against ischemia-induced stress [78]. Achieving a wider spectrum of favorable biological modifications in NSCs may prove more effective than acting on singular molecular aspects. Therefore, future studies could target a variety of these mechanisms simultaneously in order to boost the regenerative and neuroprotective potential of NSC-based transplantation therapies.

\section{Translational Perspectives for Engineering Techniques}

Despite the enormous potential of stem cell-mediated therapy for MNDs, some crucial issues still need to be addressed before allowing extensive clinical translation. NSC engineering techniques could represent a powerful aid to overcome some of these obstacles.
First, the appropriate delivery method of cells within the CNS should be optimized and standardized. In this regard, assessments and comparisons of the exact potential of different scaffolding strategies and their clinical tolerability could prove useful. Both biodegradable and non-biodegradable materials have been studied, but their safety and efficacy profile in humans has not been assessed yet. As discussed above, scaffolding techniques greatly improve the engraftment rate and may also be exploited to reduce the cellular stress connected with cell delivery. Second, confirmation of graft survival is essential to determine treatment efficacy. In many animal models, this identification is obtained through immunohistochemical identification with human-specific markers [25]. Upon clinical translation, more sophisticated techniques are needed to assess this aspect. Genetic engineering techniques could allow the detection of grafted cells, for instance through the expression of radiotracers. Another option is the use of MRI-trackable scaffolds [66].

Reduced survival of engrafted cells is a further hindrance to transplantation success. Hypoxic preconditioning and pharmacological preconditioning have proven efficient in increasing cell resilience to delivery stress and triggering expression of pro-survival genes (Tables 1 and 2). Furthermore, cells engineered to express neurotrophic factors or antioxidant genes displayed an enhanced survival rate in preclinical studies $[76,77]$. Therefore, these strategies, combined with the use of proper scaffolds, could help address these challenges. To allow clinical translation, however, safety and immunogenicity in humans need to be assessed.

Another crucial issue is represented by the oncogenic potential of transplanted cells, in particular when they are genetically modified to increase their survival. A viable strategy to overcome this issue involves the use of partially or fully differentiated cells, such as neural precursors or adult neurons, with limited proliferative capacity. Another technique to avoid neoplastic complications is represented by genetic manipulation of stem cells in order to suppress growth promoters or to insert specific genes, which can trigger apoptosis upon specific stimulation [25]. In this way, transplanted cells could be selectively targeted by cytotoxic drugs in case they undergo neoplastic transformation.

To summarize, stem cell engineering techniques are still in their infancy, but they present a striking potential for maximizing the beneficial properties of NSCs in neurological disorders. Although we are still far from their clinical application, further development of these approaches is warranted in order to expand the horizons of transplantation therapy.

\section{Conclusions and Future Perspectives}

Currently, despite extensive research efforts, no successful treatment for MNDs is available. Nonetheless, preclinical 
studies on stem cell-based transplantation therapy have yielded significant and interesting results, showing neuroprotective effects, improved functional outcomes, and delayed progression in treated groups [26, 27, 31, 34-37]. The main limitation of this approach in regard to clinical translatability is the low engraftment success and the high rate of stem cell death following transplantation. Therefore, there is a strong need for strategies aimed at addressing the issue of NSC viability and stability after transplant. Several approaches have been investigated thus far, namely, environmental stress preconditioning, biopolymer encapsulation, and genetic engineering, showing beneficial effects not only on graft integration and survival but also on the neuroprotective and immunomodulatory effects of NSCs (Fig. 1) [70-77]. Different approaches can be combined to further enhance their effects.

Nevertheless, additional studies are needed to precisely understand the molecular mechanisms that regulate cell survival after transplantation. Among the mechanisms that were identified, the hypoxic response cascade and Akt pathways appeared crucial. Moreover, the increased therapeutic effects of different preconditioning strategies seem to be due to the increased capacity of NSCs to produce and secrete neurotrophic molecules, further highlighting the importance of paracrine factors and the microenvironment in stem cell engraftment.

Hopefully, future studies on NSC transplantation will exploit these engineering techniques in the quest for a more stable and effective cellular graft. A better under- standing of the pathways involved in cellular homeostasis and in the cellular response to environmental insults, such as those leading to neurodegeneration, may suggest further potential targets for manipulation, with the aim of counteracting the cytotoxic mechanisms of neurodegener- ative diseases.

Acknowledgments The following grant support is gratefully acknowledged: Italian Ministry of Health-RF-2016-02362317 and AFM-Telethon-2015, вOptimized Transplantation of hiPSC- derived LeX+CXCR4+VLA4 neural stem cells as a therapy for SMARD1^ to GPC, and FP7-PEOPLE-2013-IRSES no. 612578

to SC. We thank the Associazione Amici del Centro Dino Ferrari for its support.

\section{Compliance with Ethical Standards}

Conflict of Interest The authors declare that they have no conflict of interest.

Abbreviations ALS, amyotrophic lateral sclerosis; BDNF, brain-derived neurotrophic factor; CNS, central nervous system; GDNF, glialderived neurotrophic factor; HMGB1, high-mobility group box 1; IPSC, induced pluripotent stem cell; MHC, major histocompatibility complex; MND, motor neuron disorder; NGF, nerve growth factor; NPC, neural progenitor cell; NSC, neural stem cell; SMA, spinal muscular atrophy; SMARD1, spinal muscular atrophy with respiratory distress type 1; VEGF, vascular endothelial growth facto

\section{References}

1. Hardiman O, Al-Chalabi A, Chio A et al (2017) Amyotrophic lateral sclerosis. Nat Publ Gr 3:17085. https://doi.org/10.1038/nrdp. 2017.85

2. Lacomblez L, Bensimon G, Leigh PN, et al (1996) Dose-ranging study of riluzole in amyotrophic lateral sclerosis. Amyotrophic Lateral Sclerosis/Riluzole Study Group II. Lancet (London, England) 347:1425-31

3. Abe K, Aoki M, Tsuji S, Itoyama Y, Sobue G, Togo M, Hamada C, Tanaka M et al (2017) Safety and efficacy of edaravone in well defined patients with amyotrophic lateral sclerosis: a randomised, double-blind, placebo-controlled trial. Lancet Neurol 16:505-512. https://doi.org/10.1016/S1474-4422(17)30115-1

4. Parente V, Corti S (2018) Advances in spinal muscular atrophy therapeutics. Ther Adv Neurol Disord 11:175628561875450. https://doi.org/10.1177/1756285618754501

5. Chen KS, Sakowski SA, Feldman EL (2016) Intraspinal stem cell transplantation for amyotrophic lateral sclerosis. Ann Neurol 79: 342-353. https://doi.org/10.1002/ana.24584

6. Gilbert SF (2000) Developmental biology. Sinauer Associates

7. Altman J, Das GD (1965) Autoradiographic and histological evidence of postnatal hippocampal neurogenesis in rats. J Comp Neurol 124:319-335

8. Kornack DR, Rakic P (1999) Continuation of neurogenesis in the hippocampus of the adult macaque monkey. Proc Natl Acad Sci U S A 96:5768-5773

9. Seri B, García-Verdugo JM, McEwen BS, Alvarez-Buylla A(2001) Astrocytes give rise to new neurons in the adult mammalian hippocampus. J Neurosci 21:7153-7160

10. Patzke N, Spocter MA, Karlsson KÆ, Bertelsen MF, Haagensen M, Chawana R, Streicher S, Kaswera C et al (2015) In contrast to many other mammals, cetaceans have relatively small hippocampi that appear to lack adult neurogenesis. Brain Struct Funct 220:361383. https://doi.org/10.1007/s00429-013-0660-1

11. Kempermann G, Kuhn HG, Gage FH (1997) More hippocampal neurons in adult mice living in an enriched environment. Nature 386:493-495. https://doi.org/10.1038/386493a0

12. Hill AS, Sahay A, Hen R (2015) Increasing adult hippocampal neurogenesis is sufficient to reduce anxiety and depression-like behaviors. Neuropsychopharmacology 40:2368-2378. https://doi. org/10.1038/npp.2015.85

13. Eriksson PS, Perfilieva E, Björk-Eriksson T, Alborn AM, Nordborg C, Peterson DA, Gage FH (1998) Neurogenesis in the adult human hippocampus. Nat Med4:1313-1317.https://doi.org/10.1038/3305

14. Sorrells SF, Paredes MF, Cebrian-Silla A, Sandoval K, Qi D, Kelley KW, James D, Mayer S et al (2018) Human hippocampal neurogenesis drops sharply in children to undetectable levels in adults. Nature 555:377-381.https://doi.org/10.1038/nature25975

15. Boldrini M, Fulmore CA, Tartt AN, et al (2018) Human hippocampal neurogenesis persists throughout aging. Cell Stem Cell 22:589599.e5. doi: https://doi.org/10.1016/j.stem.2018.03.015

16. Sabelström H, Stenudd M, Frisén J (2014) Neural stem cells in the adult spinal cord. Exp Neurol 260:44-49. https://doi.org/10.1016/j. expneurol.2013.01.026

17. Liu Z, Martin LJ (2006) The adult neural stem and progenitor cell niche is altered in amyotrophic lateral sclerosis mouse brain. J Comp Neurol 497:468-488. https://doi.org/10.1002/cne.21012

18. Chi L, Gan L, Luo C, Lien L, Liu R (2007) Temporal response of neural progenitor cells to disease onset and progression in amyotrophic lateral sclerosis-like transgenic mice. Stem Cells Dev 16: 579-588. https://doi.org/10.1089/scd.2006.0120

19. Kojima T, Hirota Y, Ema M, Takahashi S, Miyoshi I, Okano H, Sawamoto K (2010) Subventricular zone-derived neural progenitor 
cells migrate along a blood vessel scaffold toward the post-stroke striatum. Stem Cells 28:545-554. https://doi.org/10.1002/stem.306

20. Arvidsson A, Collin T, Kirik D, Kokaia Z, Lindvall O (2002) Neuronal replacement from endogenous precursors in the adult brain after stroke. Nat Med 8:963-970. https://doi.org/10.1038/ nm747

21. Khodanovich M, Kisel A, Kudabaeva M, Chernysheva G, Smolyakova V, Krutenkova E, Wasserlauf I, Plotnikov M et al (2018)Effects of fluoxetine onhippocampal neurogenesis and neuroprotection in the model of global cerebral ischemia in rats. Int J Mol Sci 19:162. https://doi.org/10.3390/ijms19010162

22. Chen J, Zhang ZG, Li Y, Wang Y, Wang L, Jiang H, Zhang C, Lu M et al (2003) Statins induce angiogenesis, neurogenesis, and synaptogenesis after stroke. Ann Neurol 53:743-751. https://doi.org/10. 1002/ana.10555

23. Corbett AM, Sieber S, Wyatt N, Lizzi J, Flannery T, Sibbit B, Sanghvi S (2015) Increasing neurogenesis with fluoxetine, simvastatin and ascorbic acid leads to functional recovery in ischemic stroke. Recent Pat Drug Deliv Formul 9:158-166

24. Dametti S, Faravelli I, Ruggieri M, Ramirez A, Nizzardo M, Corti S (2016) Experimental advances towards neural regeneration from induced stem cells to direct in vivo reprogramming. Mol Neurobiol 53:2124-2131. https://doi.org/10.1007/s12035-0159181-7

25. Faravelli I, Riboldi G, Nizzardo M, Simone C, Zanetta C, Bresolin N, Comi GP, Corti S (2014) Stem cell transplantation for amyotrophic lateralsclerosis: therapeutic potential and perspectives on clinical translation. Cell Mol Life Sci 71:3257-3268. https://doi.org/10. 1007/s00018-014-1613-4

26. Nizzardo M, Simone C, Rizzo F, Ruggieri M, Salani S, Riboldi G, Faravelli I, Zanetta C et al (2014) Minimally invasive transplantation of iPSC-derived ALDHhiSSCloVLA4+ neural stem cells effectively improves the phenotype of an amyotrophic lateral sclerosis model. Hum Mol Genet 23:342-354. https://doi.org/10.1093/ hmg/ddt425

27. Nizzardo M, Bucchia M, Ramirez A, Trombetta E, Bresolin N, Comi GP, Corti S (2016) iPSC-derived LewisX+CXCR4+ $\beta 1$ integrin+ neural stem cells improve the amyotrophic lateral sclerosis phenotype by preserving motor neurons and muscle innervation in human and rodent models. Hum Mol Genet 25:3152-3163. https://doi.org/10.1093/hmg/ddw163

28. Corti S, Locatelli F, Papadimitriou D, Donadoni C, del Bo R, Crimi M, Bordoni A, Fortunato F et al (2006) Transplanted ALDHhiSSClo neural stem cells generate motor neurons and delay disease progression of nmd mice, an animal model of SMARD1. Hum Mol Genet 15:167-187. https://doi.org/10.1093/hmg/ddi446

29. Corti S, Nizzardo M, Nardini M, Donadoni C, Salani S, Ronchi D, Simone C, Falcone M et al (2010) Embryonic stem cell-derived neural stem cells improve spinal muscular atrophy phenotype in mice. Brain 133:465-481. https://doi.org/10.1093/brain/awp318

30. Simone C, Nizzardo M, Rizzo F, Ruggieri M, Riboldi G, Salani S, Bucchia M, Bresolin N et al (2014) iPSC-derived neural stem cells act via kinase inhibition to exert neuroprotective effects in spinal muscular atrophy with respiratory distress type 1 . Stem Cell Reports 3:297-311. https://doi.org/10.1016/j.stemcr.2014.06.004

31. Teng YD, Benn SC, Kalkanis SN et al (2012) Multimodal actions of neural stem cells in a mouse model of ALS: a meta-analysis. Sci Transl Med 4:165ra164. https://doi.org/10.1126/scitranslmed. 3004579

32. Bliss T, Guzman R, Daadi M, Steinberg GK (2007) Cell transplantation therapy for stroke. Stroke 38:817-826. https://doi.org/10. 1161/01.STR.0000247888.25985.62

33. Wakai T, Narasimhan P, Sakata H, Wang E, Yoshioka H, Kinouchi H, Chan PH(2016) Hypoxic preconditioning enhances neural stem cell transplantation therapy after intracerebral hemorrhage in mice.
J Cereb Blood Flow Metab 36:2134-2145. https://doi.org/10.1177/ $0271678 X 15613798$

34. Xu L, Shen P, Hazel T, Johe K, Koliatsos VE (2011) Dual transplantation of human neural stem cells into cervical and lumbar cord ameliorates motor neuron disease in SOD1 transgenic rats. Neurosci Lett 494:222-226. https://doi.org/10.1016/j.neulet.2011. 03.017

35. Kim KS, Lee HJ, An J, Kim YB, Ra JC, Lim I, Kim SU (2014) Transplantation of human adipose tissue-derived stem cells delays clinical onset and prolongs life span in ALS mouse model. Cell Transplant 23:1585 - 1597. https://doi.org/10.3727/ $096368913 X 673450$

36. Eve DJ, Steiner G, Mahendrasah A, et al (2018) Reduction of microhemorrhages in the spinal cord of symptomatic ALS mice after intravenous human bone marrow stem cell transplantation accompanies repair of the blood-spinal cord barrier. Oncotarget 9: 10621-10634. doi: https://doi.org/10.18632/oncotarget.24360

37. Sironi F, Vallarola A, Violatto MB, Talamini L, Freschi M, de Gioia R, Capelli C, Agostini A et al (2017) Multiple intracerebroventricular injections of human umbilical cord mesenchymal stem cells delay motor neurons loss but not disease progression of SOD1G93A mice. Stem Cell Res 25:166-178. https://doi.org/10. 1016/j.scr.2017.11.005

38. Riley J, Federici T, Polak M, Kelly C, Glass J, Raore B, Taub J, Kesner Vet al (2012) Intraspinal stem cell transplantation in amyotrophic lateral sclerosis. Neurosurgery 71:405-416. https://doi.org/ 10.1227/NEU.0b013e31825ca05f

39. Glass JD, Boulis NM, Johe K, Rutkove SB, Federici T, PolakM, Kelly C, Feldman EL (2012) Lumbar intraspinal injection of neural stem cells in patients with amyotrophic lateral sclerosis: results of a phase I trial in 12 patients. Stem Cells 30:1144-1151. https://doi. org/10.1002/stem.1079

40. Feldman EL, Boulis NM, Hur J, Johe K, Rutkove SB, Federici T, Polak M, Bordeau J et al (2014) Intraspinal neural stem cell transplantation in amyotrophic lateral sclerosis: phase 1 trial outcomes. Ann Neurol 75:363-373. https://doi.org/10.1002/ana.24113

41. Glass JD, Hertzberg VS, Boulis NM, Riley J, Federici T, Polak M, Bordeau J, Fournier C et al (2016) Transplantation of spinal cordderived neural stem cells for ALS. Neurology 87:392-400. https:// doi.org/10.1212/WNL.0000000000002889

42. Goutman SA, Brown MB, Glass JD, Boulis NM, Johe K, Hazel T, Cudkowicz M, Atassi N et al (2018) Long-term phase 1/2 intraspinal stem cell transplantation outcomes in ALS. Ann Clin Transl Neurol 5:730-740. https://doi.org/10.1002/acn3.567

43. Barker RA, Widner H (2004) Immune problems in central nervous system cell therapy. NeuroRX 1:472-481. https://doi.org/10.1602/ neurorx.1.4.472

44. Tadesse T, Gearing M, Senitzer D, Saxe D, Brat DJ, Bray R, Gebel $\mathrm{H}$, Hill C et al (2014) Analysis of graft survival in a trial of stem cell transplant in ALS. Ann Clin Transl Neurol 1:900-908. https://doi. org/10.1002/acn3.134

45. Yamanaka K, Chun SJ, Boillee S, Fujimori-Tonou N, Yamashita H, Gutmann DH, Takahashi R, Misawa H et al (2008) Astrocytes as determinants of disease progression in inherited amyotrophic lateral sclerosis. Nat Neurosci 11:251-253. https://doi.org/10.1038/ nn2047

46. Rizzo F, Riboldi G, Salani S, Nizzardo M, Simone C, Corti S, Hedlund E (2014) Cellular therapy to target neuroinflammation in amyotrophic lateral sclerosis. Cell Mol Life Sci 71:999-1015. https://doi.org/10.1007/s00018-013-1480-4

47. Srivastava AK, Gross SK, Almad AA, Bulte CA, Maragakis NJ, BulteJWM(2017) Serial invivo imaging of transplanted allogeneic neural stem cell survival in a mouse model of amyotrophic lateral sclerosis. Exp Neurol 289:96-102. https://doi.org/10.1016/j. expneurol.2016.12.011 
48. Hori J, Ng TF, Shatos M, Klassen H, Streilein JW, Young MJ (2003) Neural progenitor cells lack immunogenicity and resist destruction as allografts. Stem Cells 21:405-416. https://doi.org/10. 1634/stemcells.21-4-405

49. Bakshi A, Keck CA, Koshkin VS, LeBold DG, Siman R, Snyder EY, McIntosh TK (2005) Caspase-mediated cell death predominates following engraftment of neural progenitor cells into traumatically injured rat brain. Brain Res 1065:8-19. https://doi.org/10. 1016/j.brainres.2005.09.059

50. Yu SP, Wei Z, Wei L (2013) Preconditioning strategy in stem cell transplantation therapy. Transl Stroke Res 4:76-88. https://doi.org/ 10.1007/s12975-012-0251-0

51. Bernstock JD, Peruzzotti-Jametti L, Ye D, Gessler FA, Maric D, Vicario N, Lee YJ, Pluchino S et al (2017) Neural stem cell transplantation in ischemic stroke: arole forpreconditioning and cellular engineering. J Cereb Blood Flow Metab37:2314-2319. https://doi. org/10.1177/0271678X17700432

52. Sandvig I, Gadjanski I, Vlaski-Lafarge M, Buzanska L, Loncaric D, Sarnowska A, Rodriguez L, Sandvig A et al (2017) Strategies to enhance implantation and survival of stem cells after their injection in ischemic neural tissue. Stem Cells Dev 26:554-565. https://doi. org/10.1089/scd.2016.0268

53. Fan W-L, Liu P, Wang G, Pu JG, Xue X, Zhao JH (2017) Transplantation of hypoxic preconditioned neural stem cells benefits functional recovery via enhancing neurotrophic secretion after spinal cord injury in rats. J Cell Biochem 119:4339-4351. https:// doi.org/10.1002/jcb.26397

54. Zhang G, Chen L, Guo X, Wang H, Chen W, Wu G, Gu B, Miao W et al(2018)Comparative analysis of microRNA expression profiles of exosomes derived from normal and hypoxic preconditioning human neural stem cells by next generation sequencing. J Biomed Nanotechnol 14:1075-1089. https://doi.org/10.1166/jbn.2018. 2567

55. Sakata H, Niizuma K, Yoshioka H, Kim GS, Jung JE, Katsu M, Narasimhan P, Maier CM et al (2012) Minocycline-preconditioned neural stem cells enhance neuroprotection after ischemic stroke in rats. J Neurosci 32:3462-3473. https://doi.org/10.1523/ JNEUROSCI.5686-11.2012

56. Sakata H, Narasimhan P, Niizuma K, Maier CM, Wakai T, Chan PH (2012) Interleukin 6-preconditioned neural stem cells reduce ischaemic injury in stroke mice. Brain 135:3298-3310. https://doi.org/ 10.1093/brain/aws259

57. Rosenblum S, Smith TN, Wang N, Chua JY, Westbroek E, Wang K, Guzman R (2015) BDNF pretreatment of human embryonicderived neural stem cells improves cell survival and functional recovery after transplantation in hypoxic-ischemic stroke. Cell Transplant 24:2449 - 2461. https://doi.org/10.3727/ 096368914 X679354

58. Cheng Y-H, Xia W, Wong EWP, Xie Q, Shao J, Liu T, Quan Y, Zhang T et al (2015) Adjudin-a male contraceptive with other biological activities. Recent Pat Endocr Metab Immune Drug Discov 9:63-73

59. Shao J, Liu T, Xie QR, Zhang T, Yu H, Wang B, Ying W, Mruk DD et al (2013) Adjudin attenuates lipopolysaccharide (LPS)- and ischemia-induced microglial activation. J Neuroimmunol 254:8390. https://doi.org/10.1016/j.jneuroim.2012.09.012

60. Zhang T, Yang X, Liu T, Shao J, Fu N, Yan A, Geng K, Xia W (2017) Adjudin-preconditioned neural stem cells enhanceneuroprotection after ischemia reperfusion in mice. Stem Cell Res Ther 8:248. https://doi.org/10.1186/s13287-017-0677-0

61. Xue X, Chen X, Fan W, Wang G, Zhang L, Chen Z, Liu P, Liu M et al (2018) High-mobility group box 1 facilitates migration of neural stem cells via receptor for advanced glycation end products signaling pathway. Sci Rep 8:4513. https://doi.org/10.1038/s41598-01822672-4
62. Ould-Brahim F, Sarma SN, Syal C, et al (2018) Metformin preconditioning of human induced pluripotent stem cell-derived neural stem cells promotes their engraftment and improves post-stroke regeneration and recovery. Stem Cells Dev scd.2018.0055. doi: https://doi.org/10.1089/scd.2018.0055

63. Degterev A, Linkermann A (2016) Generation of small molecules to interfere with regulated necrosis. Cell Mol Life Sci 73:22512267. https://doi.org/10.1007/s00018-016-2198-x

64. Zhong J, Chan A, Morad L, Kornblum HI, Guoping Fan, Carmichael ST (2010) Hydrogel matrix to support stem cell survival after brain transplantation in stroke. Neurorehabil Neural Repair 24:636-644. https://doi.org/10.1177/1545968310361958

65. Adil MM, Vazin T, Ananthanarayanan B, Rodrigues GMC, Rao AT, Kulkarni RU, Miller EW, Kumar S et al (2017) Engineered hydrogels increase the post-transplantation survival of encapsulated hESC-derived midbrain dopaminergic neurons. Biomaterials 136: 1-11. https://doi.org/10.1016/j.biomaterials.2017.05.008

66. Moshayedi P, Nih LR, Llorente IL, Berg AR, Cinkornpumin J, Lowry WE, Segura T, Carmichael ST (2016) Systematic optimization of an engineered hydrogel allows for selective control of human neural stem cell survival and differentiation after transplantation in the stroke brain. Biomaterials 105:145-155. https://doi.org/ 10.1016/j.biomaterials.2016.07.028

67. Somaa FA, Wang T-Y, Niclis JC, Bruggeman KF, Kauhausen JA, Guo H, McDougall S, Williams RJ et al (2017) Peptide-based scaffolds support human cortical progenitor graft integration to reduce atrophy and promote functional repair in a model of stroke. Cell Rep 20:1964-1977. https://doi.org/10.1016/j.celrep.2017.07.069

68. George PM, Bliss TM, Hua T, Lee A, Oh B, Levinson A, Mehta S, Sun $G$ et al (2017) Electrical preconditioning of stem cells with a conductive polymer scaffold enhances stroke recovery. Biomaterials 142:31-40. https://doi.org/10.1016/j.biomaterials. 2017.07.020

69. Gowing G, Svendsen S, Svendsen CN (2017) Ex vivo gene therapy for the treatment of neurological disorders. In: Progress in brain research. pp 99-132

70. Andsberg G, Kokaia Z, Björklund A, Lindvall O, Martínez-Serrano A (1998) Amelioration of ischaemia-induced neuronal death in the rat striatum by NGF-secreting neural stem cells. Eur J Neurosci 10: 2026-2036

71. Chang D-J, Lee N, Choi C, Jeon I, Oh SH, Shin DA, HwangTS, Lee HJ et al (2013) Therapeutic effect of BDNF-overexpressing human neural stem cells (HB1.F3.BDNF) in a rodent model of middle cerebral artery occlusion. Cell Transplant 22:1441-1452. https://doi.org/10.3727/096368912X657323

72. Zhang Z-H, Wang R-Z, Wang R-Z, Li GL, Wei JJ, Li ZJ, Feng M, Kang J et al (2008) Transplantation of neural stem cells modified by humanneurotrophin-3promotes functional recovery after transient focal cerebral ischemia in rats. Neurosci Lett 444:227-230. https:// doi.org/10.1016/j.neulet.2008.08.049

73. Chen B, Gao X-Q, Yang C-X, Tan SK, Sun ZL, Yan NH, Pang YG, Yuan M et al (2009) Neuroprotective effect of grafting GDNF genemodified neural stem cells on cerebral ischemia in rats. Brain Res 1284:1-11. https://doi.org/10.1016/j.brainres.2009.05.100

74. Zhu W, Mao Y, Zhao Y, Zhou LF, Wang Y, Zhu JH, Zhu Y, Yang GY (2005) Transplantation of vascular endothelial growth factortransfected neural stem cells into the rat brain provides neuroprotection after transient focal cerebral ischemia. Neurosurgery 57: 325-333 discussion 325-33

75. Zhu J, Zhao Y, Chen S, Zhang WH, Lou L, Jin X (2011) Functional recovery after transplantation of neural stem cells modified by brain-derived neurotrophic factor in rats with cerebral ischaemia. J Int Med Res 39:488 - 498. htt ps://doi.org/10.1177/ 147323001103900216

76. Thomsen GM, Avalos P, Ma AA, Alkaslasi M, Cho N, Wyss L, Vit JP, Godoy M et al (2018) Transplantation of neural progenitor cells 
expressing glial cell line-derived neurotrophic factor into the motor cortex as a strategy to treat amyotrophic lateral sclerosis. Stem Cells 36:1122-1131. https://doi.org/10.1002/stem.2825

77. Sakata H, Niizuma K, Wakai T, Narasimhan P, Maier CM, Chan PH (2012) Neural stem cells genetically modified to overexpress cu/ Zn-superoxide dismutase enhance amelioration of ischemic stroke in mice. Stroke 43:2423-2429. https://doi.org/10.1161/ STROKEAHA.112.656900

78. Yang W, Sheng H, Wang H (2016) Targeting the SUMO pathway for neuroprotection in brain ischaemia. BMJ 1:101-107. https://doi. org/10.1136/svn-2016-000031

79. Theus MH, Wei L, Cui L, Francis K, Hu X, Keogh C, YuSP (2008) In vitro hypoxic preconditioning of embryonic stem cells as a strategy of promoting cell survival and functional benefits after transplantation into the ischemic rat brain. Exp Neurol 210:656-670. https://doi.org/10.1016/j.expneurol.2007.12.020
80. Wei L, Fraser JL, Lu Z-Y, Hu X, Yu SP (2012) Transplantation of hypoxia preconditioned bone marrow mesenchymal stem cells enhances angiogenesis and neurogenesis after cerebral ischemia in rats. Neurobiol Dis 46:635-645. https://doi.org/10.1016/j.nbd. 2012.03.002

81. Sun J, Wei ZZ, Gu X, Zhang JY, Zhang Y, Li J, Wei L (2015) Intranasal delivery of hypoxia-preconditioned bone marrowderived mesenchymal stem cells enhancedregenerative effects after intracerebral hemorrhagic stroke in mice. Exp Neurol 272:78-87. https://doi.org/10.1016/j.expneurol.2015.03.011

82. Wei ZZ, Lee JH, Zhang Y, Zhu YB, Deveau TC, Gu X, Winter $\mathrm{MM}, \mathrm{Li} \mathrm{J}$ et al (2016) Intracranial transplantation of hypoxiapreconditioned iPSC-derived neural progenitor cells alleviates neuropsychiatric defects after traumatic brain injury in juvenile rats. Cell Transplant 25:797- 809. https://doi.org/10.3727/ 096368916 X690403 